\title{
A Psicologia dos Jesuítas: Uma Contribuição à História das Idéias Psicológicas
}

\author{
Marina Massimi ${ }^{1}$ \\ Universidade de São Paulo, Ribeirão Preto
}

\begin{abstract}
Resumo
O trabalho pertence ao domínio da História das Idéias Psicológicas, entendida como parte da História Cultural cujo objeto é o estudo dos conceitos referidos ao ambiente cultural onde foram construídos. Portanto, aparece clara a pertinência de uma linha de pesquisa que investigue o significado dos conhecimentos psicológicos no âmbito da área multifacetada da cultura, ao longo do tempo. O presente estudo aborda os conceitos acerca dos fenômenos psicológicos formulados no âmbito da literatura espiritual e da produção filosófica da Companhia de Jesus ao longo dos séculos XVI e XVII. A experiência psicológica é interpretada em termos das noções elaboradas pelos tratados filosóficos, os quais por sua vez fundamenta-se na tradição aristotelico-tomista. A "psicologia" jesuítica possui uma dimensão filosófica, relativa ao ensino e à produção intelectual da Companhia, juntamente a uma dimensão prática, fundada na antiga tradição da Medicina do ânimo.

Palavras-chave: História das Idéias Psicológicas; História da Psicologia Jesuítica.
\end{abstract}

\begin{abstract}
The Jesuitic "Psychology": A Contribution to the History of Psychological Ideas

The work concerns the area of History of psychological ideas, considered to be part of Cultural History, its subjects being relative to the cultural milieu in which they are constructed. In this respect, one can also see the pertinence of a research program that investigates the meanings of psychological knowledge within the multifaceted area of culture along its history. The present study deals with the conceptual view of the psychological phenomenon in spiritual literature and in philosophical production of Jesuit scholars throughout the sixteenth and seventeenth century. The psychological experience is interpreted according to the notions elaborated in the philosophical treatise, which in turn are based on the Aristotelian-Thomistic tradition. The Jesuit psychology has a philosophical dimension, concerned with the teaching and the philosophical production of the Company - and a practical dimension, connected with ancient tradition of Medicine of the Soul.

Keywords: History of psychological ideas; Jesuit psychology.
\end{abstract}

No século XVI, os pensadores da Companhia de Jesus, ordem religiosa fundada por Inácio de Loyola visando a realizar uma síntese entre a herança do catolicismo medieval e o novo espírito renascentista, encarregam-se de "traduzir" tais concepções num método de formação do homem, seja em seu percurso evolutivo da infância até à maturidade pela educação, seja no que diz respeito à aculturação dos povos ameríndios, africanos e orientais, através do processo de cristianização. Nesse âmbito, o conhecimento da subjetividade, por um lado, e da dinâmica das relações sociais, por outro, aparecem como instrumentos necessários e, num certo sentido, privilegiados.

No Brasil, ao longo de pelo menos dois séculos, os jesuítas constituíram-se numa presença cultural e social significativa. Apesar de estarem mergulhados no contexto

\footnotetext{
${ }^{1}$ Endereço para correspondência: Departamento de Psicologia e Educação, Faculdade de Filosofia Ciências e Letras, Campus USP, Av. Bandeirantes, 3900, 14040-901, Ribeirão Preto, SP. E-mail: mmassimi3@yahoo.com
}

do regime colonial, profundamente imbuído por contradições e conflitos, e submetidos às regras e aos jogos do poder régio, os missionários da Companhia foram responsáveis pela criação da primeira rede de ensino no país e pela construção de numerosas obras, visando à integração das culturas indígenas e das culturas européias. Destacam-se, entre outras, as peças teatrais e poéticas e o compêndio da gramática da língua tupi - guarani, redigidas por José de Anchieta (1988).

A importância da contribuição da Companhia de Jesus na elaboração do saber e da ciência ocidentais, a partir do século XVI, tem sido recentemente apontada por vários estudiosos. A historiografia da ciência e da pedagogia jesuítica constitui-se hoje numa área muito importante de atuação dos historiadores da ciência e da cultura (Andrade, 1981; Caeiro, 1982, 1989; Giard, 1995; Giard \& Vaucelles, 1996; Maravall, 1997; Rodrigues, 1985).

No que diz respeito especificamente à História das Idéias Psicológicas, deve-se destacar o aporte dos jesuítas à criação de formas, métodos e justificativas para a construção de um tipo de conhecimento da subjetividade e do comportamento humanos muito relevante para a 
definição dos alicerces conceituais que darão origem à Psicologia moderna. Com efeito, o saber psicológico proposto pelos jesuítas não é de natureza puramente filosófica e exclusivamente especulativa, mas proporciona uma abordagem aos fenômenos psíquicos visando ao entendimento e controle em função das exigências da vida individual e social. Nessa perspectiva, práticas, tais como a direção espiritual, e o exame de consciência, construídas e utilizadas sistematicamente pelos jesuítas em seus colégios, podem ser consideradas ferramentas significativas no processo de elaboração daquele tipo de competência que será posteriormente chamada de Psicoterapia.

O objetivo do presente artigo é o de apresentar um quadro sintético das diversas dimensões de conhecimentos e práticas psicológicas, elaborados no âmbito da Companhia, entre os séculos XVI e XVII. Com efeito, a "psicologia" jesuítica possui duas dimensões: uma estritamente especulativa, ligada ao ensino e à produção filosófica no âmbito da Ordem, e outra mais prática, dimensão que, por sua vez, se enxerta numa longa tradição doutrinária de origem grega e romana, denominada de Medicina do Ânimo ou Medicina da Alma.

\section{A Psicologia Filosófica e suas Matrizes Aristotélico- Tomistas}

No presente trabalho, foram, em primeiro lugar, analisadas as categorias teóricas utilizadas no âmbito do saber elaborado pela Companhia de Jesus, no período considerado, para definir a dimensão psicológica da experiência humana, bem como os fenômenos a esta relacionados. Para tanto, abordou-se o estudo da psicologia filosófica elaborada pelos pensadores da Companhia, em obras cuja influência no contexto luso-brasileiro foi marcante: trata-se dos assim chamados tratados Conimbricences, redigidos pelos professores do Colégio das Artes da Companhia em Coimbra, e que, posteriormente, foram utilizados para os estudos filosóficos nos colégios da Companhia no Brasil (Barreto, 1983; Caeiro, 1982; Martins, 1989; Santos, 1955; Tavares, 1948). Os tratados são comentários das obras aristotélicas. No caso do estudo psicológico, trata-se dos seguintes textos: o comentário ao tratado De Anima (Sobre a Alma, Gois, 1602), o comentário ao tratado Parva Naturalia (Pequenas coisas naturais, Gois, 1593a), o comentário ao tratado Etica a Nicomaco (Gois, 1593b), o comentário ao De Generatione et Corruptione (Sobre a geração e a corrupção, Gois, 1607). No âmbito dos referidos textos - todos redigidos em idioma latino - evidenciaram-se os principais conceitos referentes ao conhecimento psicológico.
Algumas teses fundamentais referentes à definição aristotélico-tomista da alma humana, constituem-se nos alicerces do saber proposto, buscando investigar a natureza dos fenômenos do psiquismo humano. Em primeiro lugar, destaca-se a definição de alma como ato primeiro substancial do corpo, forma do corpo e princípio da nossa atividade, definição esta que remonta à doutrina aristotélica clássica (Aristóteles, edições de 1993, 1994, 1996). A alma possui capacidades peculiares, que, na linguagem da dita doutrina, são denominadas de potências. São elas: a potência vegetativa; a sensitiva (a saber, a capacidade sensorial proporcionada pelos sentidos internos e externos), a locomotora, a apetitiva (sensitiva e intelectiva); a cogitativa ou estimativa e a potência intelectiva (intuitiva e abstrativa). Na realidade, as potências da alma correspondem ao que hoje a psicologia moderna define como funções psíquicas, notadamente: as funções sensoriais, as funções motivacionais e emocionais, as funções intelectuais. Todavia, na perspectiva da psicologia aristotélica, as potências não se identificam tout court com os fenômenos, ao passo que a psicologia moderna reconhece existência apenas dos fenômenos, tendo sido inclusive esta diferenciação o salto decisivo para o nascimento da ciência psicológica no século XIX.

A reproposição da psicologia aristotélica pelos jesuítas passa pela interpretação que dela foi realizada pelo filósofo e teólogo Tomás de Aquino (edição e tradução brasileira: 1980), no século XIII, assumindo, portanto a denominação de doutrina aristotélico-tomista. Todavia, para além da continuidade com esta tradição filosófica medieval, os pensadores jesuítas de Coimbra sofrem a influência das mudanças culturais, que marcam o período humanista e renascentista, ao qual pertencem. Devese a tal influência, por exemplo, o fato de que, na discussão dos Conimbricences, as teses e as questões ${ }^{2}$ referentes à dinâmica das potências psicológicas sejam enfrentadas inclusive no plano do comportamento humano, acarretando a interseção entre os domínios da Psicologia e da Ética. Com efeito, o Humanismo e, sobretudo a Renascença - devido à ênfase na visão do homem como fažedor de si mesmo (Cassirer, 1977; Garin, 1995) - revisitaram o pensamento ético de Aristóteles, sendo que por isto a Ética a Nicomaco (Aristóteles, 1996) foi um dos livros mais lidos e interpretados pelos pensadores daquele período, inclusive pelos intelectuais da Companhia de Jesus. 2 A organização do texto em questões, soluções e teses, corresponde à
estrutura do método escolástico herança da filosofia medieval. 
A dinâmica psíquica que dá origem às ações humanas é a resultante da interseção e interação entre a vontade, o intelecto e o desejo e o apetite sensitivo (cuja definição daremos a seguir). Todavia, na esteira do pensamento da época, os Conimbricences supõem que haja uma relação de dependência entre as demais potências da alma e a vontade e por isto detêm-se na análise da dinâmica pela qual a vontade move as demais potências.

Para tanto, o elemento básico é a noção de desejo, que - na tradição do aristotelismo - consiste na apetição, ou seja, na inclinação de todas as coisas para o bem. Distingue-se entre o apetite inato e o apetite aprendido (elícito) - pois a ênfase na formação do homem pela educação própria dos séculos XV e XVI ressalta a importância da aprendizagem. $\mathrm{O}$ apetite inato distingue-se em natural sensitivo (concupiscência) e natural intelectivo (vontade).

Os Conimbricences, assim como toda a cultura do seu tempo, atribuem grande importância aos estados da alma definidos como paixões, e que na linguagem da psicologia moderna correspondem às emoções ou sentimentos. As paixões são entendidas como movimentos do apetite sensitivo, provenientes da apreensão do bem ou do mal, acarretando algum tipo de mutação não natural do corpo. Neste sentido, elas dependeriam sempre de uma representação que o intelecto faz de algum objeto julgado como bom ou mau. As paixões são classificadas na base de uma distinção intrínseca do apetite sensitivo, em concupiscivel e irascivel. No primeiro caso, o desejo mobiliza-se na direção do bem reconhecido como tal, no segundo caso, busca a apreensão de um bem árduo. $\mathrm{O}$ apetite sensitivo tem sua localização orgânica no coração.

Os Conimbricences aprofundam especialmente a questão das relações entre as paixões e o intelecto. Discutem a contraposição das teses estóicas e das teses aristotélicotomistas a respeito deste tópico, contraposição esta que originara um significativo debate no contexto cultural da época. Divergindo da posição estóica que considera paixões como fenômenos nocivos à saúde psíquica e física do ser humano, propõem a necessidade de que elas sejam extirpadas enquanto doenças do ânimo e vícios morais, os filósofos jesuítas reafirmaram a função positiva das paixões - já conclamada por Aristóteles e Tomás. Com efeito, se forem ordenadas pela razão, as paixões colaboram à sobrevivência do homem e, além do mais, ajudam-no a alcançar a virtude. As paixões podem ser definidas como doenças ou distúrbios do animo apenas enquanto se afastam da regra e moderação da razão.

Os Conimbricences atribuem grande importância também às questões acerca dos correlatos fisiológicos e biológicos da dinâmica das paixões, tais como: as relações entre a tristeza, o sono e os sonhos; as relações entre os

Psicologia: Reflexão e Crítica, 2001, 14(3), pp. 625-633 sonhos e as paixões; as relações entre as paixões, o sistema cárdio-vascular e a respiração; as relações entre as paixões e a constituição psicossomática dos indivíduos (temperamento); as relações entre as paixões e as diversas idades da vida. Afirmam os efeitos benéficos do sono no controle das paixões. Discutem os casos de óbitos ou de doenças induzidas por paixões de excessiva intensidade (especialmente os excessos na ira, no medo, na tristeza, ou na alegria). Analisam os efeitos somáticos de algumas paixões, tais como o empalidecer e o tremor induzido pelo medo, a sede e o arrepio de cabelos, em decorrência do medo; as relações complementares entre diversas paixões (por exemplo, entre a ira, a tristeza, a dor e o prazer) e os nexos entre o amor e a loucura.

Numa avaliação de conjunto, pode-se dizer que a psicologia dos Conimbricences é doutrina de cunho aristotélico-tomista, apesar de receber influências do platonismo e do estoicismo - conforme a reproposição que destas correntes filosóficas fez a cultura renascentista. Além do mais, os autores são abertos a uma vasta gama de influências, algumas próprias da tradição filosófica anterior, outras características do contexto intelectual do Humanismo e da Renascença, influências estas de teor mais propriamente filosófico, mas também médico ou de outras áreas da "filosofia natural". Cita-se, repetidamente, entre outros, os filósofos Marsilio Ficino, Pico della Mirandola, Niccoló Pomponazzi e o médico Vesalio. Desse modo, a análise dos comentários às obras psicológicas aristotélicas, das questões colocadas, das soluções apresentadas, refutadas ou aceitas, permite conhecer o panorama amplo da época no que diz respeito à sua visão antropológica e psicológica. Especialmente, permite-nos entender os problemas, as soluções, os temas e os conceitos, os métodos de conhecimento, que na época eram considerados componentes essenciais do domínio definido como estudo da "anima".

Nessa perspectiva, fica evidente que a "Psicologia" dos Conimbricences - mesmo não apresentando características totalmente originais (pois se conforma à tradição dos Antigos no que diz respeito à sua estrutura teórica) é expressiva da posição cultural da nascente modernidade. Sobretudo são significativos os recortes que os tratados atuam neste domínio de conhecimento - apontando para questões e privilegiando ou inventando soluções sugeridas pelos interesses e pelas preocupações específicos da época. Não é casual, por exemplo, o grande espaço dedicado no Comentário ao De Anima (Gois, 1602) à questão das diferenças individuais quanto à alma humana. Este tema - já abordado por Tomás de Aquino na Suma Teológica (1980) de forma um tanto duvidosa e interpretado pelos filósofos peripatéticos de diferentes maneiras, é tratado 
com grande ênfase pelo autor jesuíta do Comentário, o professor Manuel de Góis, no capítulo referente às qualidades da alma. Aqui, afirma-se com firmeza que, no que diz respeito à alma e às suas potências, os homens de todas as raças e de todos os tempos, são iguais. Desse modo, a deficiência ou a perfeição quanto às operações da mesma potência não devem ser atribuídas a menor ou maior perfeição da potência, e sim ao defeito ou à perfeição do órgão empregado (vide artigo II, capítulo I, quaestio V, em Gois, 1602). Toda desigualdade que existe de indivíduo para indivíduo, no que diz respeito à inteligência, provém somente da desigualdade de constituição dos corpos individuais. A importância da discussão fica clara, ao lembrarmos o debate travado por teólogos e filósofos católicos contemporâneos, especialmente na área ibérica, acerca da humanidade dos povos ameríndios ${ }^{3}$. Um exemplo disto, no âmbito jesuítico, encontra-se no Diálogo acerca da conversão do gentio, elaborado por Manoel da Nóbrega (1988) em meados do século XVI, onde se discute a questão da evangelização do índio brasileiro. Este documento, um dentre muitos, evidencia a importância de uma atenta leitura dos tratados Conimbricences, pois apesar de apreciações negativas repetidamente feitas por historiadores da filosofia acerca de seu conteúdo ${ }^{4}$, apresentam-se sobremaneira densos de assuntos importantes para o período em que foram elaborados - o que demonstra que os tratados não foram uma simples e insignificante repetição da teoria aristotélicotomista medieval. Evidentemente, esta leitura apresentase especialmente difícil devido ao idioma latino e à complexidade do raciocínio, que, porém, sempre brilha por clareza lógica e rigor conceptual.

Sintetizando, podemos dizer que o aspecto mais importante do estudo dos tratados é o de proporcionar uma visão do recorte que o saber jesuítico, em seu tempo, opera no que diz respeito à psicologia filosófica de tradição aristotélico-tomista, à luz dos problemas contemporâneos e, sobretudo, da revolução produzida no âmbito do conhecimento pela descoberta de Novos Mundos, de novos homens, novos povos e formas sociais.

\section{A Medicina do Animo}

No que diz respeito à segunda dimensão da "Psicologia" jesuítica, a da Medicina da Alma ou do Animo (na terminologia da filosofia estóica), esta - como já frisamos - remete à longa tradição que, iniciada por Platão,

\footnotetext{
${ }^{3}$ Acerca desta discussão lembre-se as obra clássica de L. Hanke (1985)

${ }^{4}$ Entre outros, por destacados historiadores da filosofia brasileiros (Paim,1974).
}

Demócrito, Hipócrates, Cícero, Sêneca e Galeno, consolidou-se ao longo da Idade Média, sendo retomada e ampliada no Humanismo e na Renascença. Baseada numa analogia entre a alma e o corpo, a Medicina da Alma pressupõe a existência das enfermidades da alma, ou seja, a especificidade da patologia psicológica (Crombie, 1987; Klibansky, Panofsky \& Saxl, 1983). Neste sentido, o conceito de "doença da alma" repousa numa tomada de consciência médica - pois se trata de uma doença - e ao mesmo tempo filosófica - sendo a alma o objeto acometido pela moléstia. Tal analogia é, em muitos casos, interpretada em termos de um paralelismo, em outros, como expressiva da unidade psicossomática que caracteriza o ser humano. O principio unitário da saúde é o equilíbrio, de modo que qualquer desequilíbrio, seja no corpo seja no espírito, é causa de doença. É assim que, por exemplo, um desequilíbrio no sentido de um excesso ou defeito nos movimentos do apetite sensorial (=paixão), pode provocar doenças corporais e psíquicas. Da mesma forma, a diversidade na composição dos humores do corpo (complexão) origina diferentes temperamentos psicológicos, mas um excesso ou defeito de um ou outro humor pode degenerar em patologias psíquicas e físicas.

O filósofo estóico Sêneca, em sua obra Sobre a tranquiilidade da alma (1994) elabora um dos textos de referência desta concepção. A obra estrutura-se em forma de diálogo, como verdadeira consulta médica: o interlocutor de Sêneca, Sereno, descreve-lhe seu estado psíquico (habitus) como a um médico (ut medicus), descreve-lhe os sintomas e solicita-lhe um diagnóstico (vide também Sêneca, 1980).

No universo mental e cultural do Ocidente, marcado pelo cristianismo, a Medicina da Alma assume também dimensão propriamente religiosa e espiritual, de modo que começa a ser rotulada também como Medicina do Espirito. $\mathrm{Na}$ mentalidade do ocidente medieval e renascentista, a Medicina da Alma corresponde à "ciência" ou à "arte de viver". Desse modo, teologia, filosofia e medicina encarregam-se de construir o domínio da Medicina da Alma - cada uma com suas competências e perspectivas próprias - e é assim que este domínio vem abarcar um conjunto de conhecimentos de vária natureza, desde as teorias médicas (como, por exemplo, a teoria humoralista) até aos conselhos sugeridos pela sabedoria dos Padres do deserto, da antiga tradição da Patrística cristã. A teoria humoralista - cujas origens remontam a Hipócrates e Galeno, considera a constituição do homem determinada pela presença de quatro bumores fundamentais que, por sua vez, correspondem aos quatro elementos básicos da composição do Universo. Os humores são: bílis preta (melancolia), bílis amarela, fleu- 
ma e sangue. Conforme o predomínio de um destes na constituição dos indivíduos, tem-se quatro tipos de temperamentos: melancólico, colérico, fleumático e sangüíneo. Os temperamentos, por sua vez, determinam as características psicossomáticas do sujeito: sua condição orgânica bem como seus estados psíquicos (Klibansky, Panofsky \& Saxl, 1983). ${ }^{5}$

Os humanistas assumem a tarefa de traduzir os conteúdos destes conhecimentos em normas da "arte do viver", e é assim que, entre outros, o humanista dálmata Marculus Marulus escreve o tratado De Bene beateque vivendi e seu mestre italiano Tideu Acciarini compõe, em 1489, o De Animorum Medicamentis (Massimi, 1983). O médico espanhol Huarte de San Juan, formado pela Universidade de Alcalá e autor do Examen de Ingenios para las Sciencias (1574), estabelece estreita correspondência entre a Medicina do corpo, a Medicina do Animo e a construção política e social da sociedade, baseando-se no modelo da República platônica. Desse modo, a prática social apóiase na filosofia natural, sendo o corpo social estruturado em analogia com o microcosmo que é o homem (San Juan, 1989).

Os jesuítas dão continuidade a esta tradição e difundem-na, inclusive em seus âmbitos de presença missionária, como o Brasil. Já nos escritos de Inácio de Loyola, fundador da Ordem religiosa, vemos a referência freqüente a esta tradição de conhecimentos, em função do entendimento mais profundo do ser humano e de seu destino, visando à orientação (direção) de sua vida espiritual. Assim, por exemplo, em carta escrita ao Padre Antônio Brandão em junho de 1551, Loyola frisa a importância de que o mestre espiritual conheça o temperamento daquele que se entrega aos seus cuidados, afirmando a necessidade de "acomodar-se à complexão daquele com quem se conversa, a saber, se é fleumático ou colérico, etc (..), e isto com moderação.” (Loyola, 1993, vol. 2, p. 89)

A mesma "arte de viver" Loyola demostra ao indicar algumas regras de convivência ao Padres Broett e Salmerón, (carta escrita de Roma, setembro de 1541):

"Nos negócios com toda a gente, principalmente com iguais ou inferiores em dignidade, falar pouco e esperar, ouvir

\footnotetext{
5 A teoria dos humores estabelece uma correspondência entre a preponderância de um tipo de humor no organismo humano e o temperamento do indivíduo. Desse modo, ao excesso de bílis negra (melanê kolê) corresponde o temperamento melancólico; ao excesso de bílis amarela corresponde o colérico; ao excesso de sangue, o sangüíneo; ao excesso de água, o fleumático.
}

Psicologia: Reflexão e Crítica, 2001, 14(3), pp. 625-633 muito e de bom grado; sim, escutar longamente até acabarem de dizer o que querem. Depois disso, responder em diversos pontos, concluindo e despedindo-se. Se retomarem a questão, abreviar as respostas no que for possível. A despedida, embora rápida, seja amável. No trato de pessoas de qualidades insignes, procurar ganhar-lhes a afeição para maior serviço de Deus Nosso Senhor. Para isso atender primeiro ao seu temperamento e adaptar-se a ele. Se são coléricos e falam com viveza, tomar um pouco seu modo em bons e santos assuntos; para esses, nada de grave, lento ou melancólico. Mas com os sérios, lento no falar, graves e pesados, tomar também o modo deles, porque isto lhes agrada: 'Fiz-me tudo para todos'. Advirta-se o seguinte: se alguém é de temperamento colérico e trata com outro colérico, se não são de um mesmo sentir, há grandíssimo perigo de se desajustarem suas conversas. Portanto, se um conhece ser de compleição colérica, deve ir, em todos os pontos do negócio, muito armado de consideração, com decisão de suportar e não altercar com o outro, principalmente se sabe que é doente. Mas se tratar com fleumático ou melancólico, não há tanto perigo de desajuste por palavras precipitadas." (Loyola, 1993, vol. 3, pp. 21-22).

Cláudio Acquaviva (1543-1615), um dos sucessores de Inácio na Generalado da Companhia, foi autor, entre outros, das Industriae ad curandos animi morbos (Normas para a cura das enfermidades do ânimo, 1600; ed. 1893), destinado a todos os Superiores da Companhia visando à orientação da formação espiritual de seus discípulos. Neste texto, Acquaviva retoma a analogia tradicional entre doenças (e cura) do corpo e enfermidades (e terapia) da alma, definindo os vários tipos de doenças espirituais e os remédios necessários para cada uma, inspirando-se na tradição monástica e patrística (São Basílio, São Gregório, São Bernardo, Santo Agostinho, entre outros).

O mesmo Claudio Acquaviva, na Instructio ad reddendam rationem conscientiae iuxta morem Societatis Iesu (Normas para o exame de consciência) institui oficialmente - como "perpetua praxi Societatis" (Acquaviva, 1893, Vol. 2, p. 257) a prática do exame de consciência, tendo função de auto conhecimento, de prevenção e cuidado de si mesmo. Através desta prática, o religioso deveria desvelar integralmente a alma humana para seu diretor espiritual: “totam animam suam integre manifestam faciat" (Acquaviva, 1893, p. 34). Acquaviva propõe na "Instrução" um roteiro de perguntas para orientar os diretores espirituais: entre outras, uma questão visa detectar os casos em que o sujeito experimente algumas "animi perturbationes" (1893, p. 34). Ao justificar a introdução do exame de consciência, Acquaviva retoma a discussão, acerca da necessidade de se estabelecer uma medicina do ânimo, análoga à medi- 
cina do corpo. ${ }^{6}$ Além disso, afirma que, neste exercício, descobrem-se as diferenças individuais:

"Perché sono diversi i moti interiori dell'huomo: chi sará timido, chi audace, chi colerico, etc (...); peró si deve ció dire, cioé da quale passione si sente piú affliggere, et darsi fastidio, se si sente molto dato alla superbia, alla propria esistimatione et honore, se si sente essere colerico, et che per ogni picciola cosa dettali si risente et perturba, se é timido, che per ogni picciola cosa resta spaventato, etc..." (tradução: "Pois os movimentos interiores do homem, são diversos: um é tímido, outro audaz, outro colérico, etc. ..Todavia, é preciso declarar qual seja a paixão que mais nos atormenta e aflige; é preciso reconhecer se nós nos sentirrmos muito tentados pela soberba, pelo amor próprio, ou se somos muito coléricos de modo que ficamos irritados por qualquer pequena correção, ou se somos tímidos de modo que nos amedrontamos por qualquer coisa." (manuscrito n. 429 - ARSI, folha 34).

A qualidade de colérico faz parte aqui do perfil da personalidade que o sujeito é convidado a reconhecer e a retratar, num discurso elaborado para si mesmo e para o médico espiritual. Cabe ressaltar também o valor preventivo e terapêutico atribuído por Acquaviva a este exercício, mais uma vez definido num quadro comparativo com a ciência médica:

"L'esempio della medicina conviene molto all'effetto, che fa la confessione. (...) Si che l'istesso effetto faccia all'anima la confessione che al corpo la medicina." (tradução: O exemplo da medicina muito convém para explicar o efeito da confissão (...) De modo que a confissão tem para o ânimo o mesmo efeito que a medicina para corpo; manuscrito n. 429 - ARSI, folhas 35-35v).

A partir de Aquaviva, a expressão Medicina da Alma comparece sistematicamente na literatura jesuítica. A utilização deste saber em função prática no plano da orientação espiritual, da atividade missionária e pedagógica, parece-nos o aspecto mais original da contribuição que a Companhia de Jesus deu à história das idéias psicológi-

\footnotetext{
${ }^{6} \mathrm{La}$ terza ragione (da instituição do exame de consciência, ndr), é vedere che in quest' atto veniamo ad essere aiutati per sanarci dall' infermitá spirituale. Perché sí come quando uno sta male nel corpo si ha grande cura, acció si vegghi quanto para à risanare, cosí maggiormente si viene a fare in quest'atto particolare l'huomo mostrando le sue infermitá al medico spirituale. Et si come quando uno sta male nel corpo si ha giá cura, acció si vegghi quanto porta a risanare, cosí maggiormente si viene a fare in quest'atto particolare, l'huomo mostrando le sue infermitá al medico spirituale. Et sí come non puó il medico dar buon rimedio all'ammalato se tutto il male non si scuopre, cosí ne anco il medico spirituale potrebbe medicarci, se non le diciamo tutto il nostro male. Né peró si deve far poco conto delle cose picciole, perché interviene à punto come all'ammalato, il quale pensando che qualche male sia di poca importanza, per tal pensiero non lo scuopre al medico. Quando poi vá...cresce il male, in modo che é difficile il curarsi e bisogna molte volte tagliare il membro marcio, e guasto. (ms. 429, ARSI, folha 33).
}

cas. Com efeito, trata-se de um conhecimento do ser humano e de sua dinâmica psicológica visando à adaptação deste ao contexto social de inserção (a comunidade religiosa e o ambiente em que esta desenvolve sua missão no mundo). Esta concepção (a necessidade de um conhecimento visando à modificação do objeto para alcançar determinados objetivos) é característica da modernidade, sendo esta exigência o fundamento inclusive para a constituição da psicologia científica moderna.

\section{Dois Exemplos Significativos}

Apontamos, a seguir, dois exemplos muito significativos da utilização da psicologia filosófica e da Medicina da Alma no âmbito da Companhia de Jesus. No primeiro, a teoria dos temperamentos e as categorias derivadas da psicologia filosófica são utilizadas em função do conhecimento de si mesmo e das próprias motivações, no processo de formação de jovens jesuítas e, especificamente, na construção de seu projeto de vida. Resultados deste processo podem ser apreendidos pela análise das cartas Indipetae, documentos redigidos pelos jovens membros da Companhia e destinadas ao Superior Geral de Roma - que se encontram manuscritas no Arquivo Histórico da Cúria Geral da Companhia em Roma. O objetivo dessas cartas era a explicitação das motivações que levavam estes jovens a pedir o envio para as missões além mar (genericamente definidas como Índias). Daqui o nome latino de Indi-petae (=pedido das Índias).

Nem todos os pedidos eram atendidos pelo Superior: o método de avaliação baseava-se na leitura das cartas e no conhecimento de seus autores através de informações fornecidas pelo Padre Provincial, o mestre dos noviços e os Catálogos Trienais (acerca dos quais trataremos a seguir). O critério de avaliação dos Superiores para decidir o envio dos jovens missionários fundamentavase na análise das motivações descritas nas cartas: em primeiro lugar, a conformidade do solicitante ao perfil ideal (antropológico e religioso) do jesuíta - assim como definido pelo fundador Inácio de Loyola em sua vida e em seus escritos bem como pela literatura de espiritualidade da Companhia. Em segundo lugar, examinavam-se as circunstâncias da vida do sujeito: as relações com os familiares, a idade, as aptidões demonstradas ("talentos"), os conhecimentos adquiridos, seu estado psicossomático ("compleição", ou temperamento). Por parte dos autores, que nas cartas relatam sua história de vida, antes e depois da entrada na Companhia, a ênfase cai no "desejo" e nos sentimentos experimentados diante da perspectiva da missão além mar, no processo de imitação de alguma figura ideal (da Companhia), em alguns casos, na confirmação do desejo recebida por si- 
nais interpretados como divinos (sonhos, encontros, fatos ocorridos). Em muitos casos, os pedidos não eram atendidos.

Vários insistem no assunto escrevendo repetidas cartas, cujo tom é cada vez mais apelativo e marcado pela insistência no desejo das Índias. Apesar da escritura das Indipetae ser instituída por uma norma do Padre Geral da Companhia, visando disciplinar e tomar conhecimentos dos pedidos para o envio em missão parece não existir uma normativa quanto às formulas para a redação das mesmas - fato esse que as particulariza com relação ao restante corpus de correspondência epistolar elaborado no âmbito da Ordem. Nesse sentido, os documentos podem ser considerados parcialmente expressivos da experiência subjetiva de seus autores, dentro dos moldes que, na época, codificavam a expressão da experiência individual pela escrita.

Um segundo exemplo de utilização da Medicina da Alma, especificamente da teoria dos temperamentos e das categorias psicológicas da filosofia aristotélico-tomista, é constituído pela elaboração dos perfis de cada membro da Companhia nos Catálogos Trienais redigidos por cada comunidade jesuítica, por ordem do Padre Geral da Companhia. Inicialmente tratava-se de simples listagem dos membros da Companhia (noviços e professos) presentes em cada casa ou colégio. Esta listagem devia ser enviada a cada três anos ao Padre Geral em Roma, para que este pudesse ter conhecimento claro do estado da Companhia espalhada pelo mundo, naquele momento. Posteriormente, nas últimas décadas do século XVI, por ordem do Padre Geral, os termos de elaboração da lista tornaram-se mais complexos e detalhados.

Os Catálogos organizam-se em três partes: o Catálogo Primeiro, fornecendo informações acerca de cada jesuíta, da idade, proveniência e formação, tempo de pertença à Companhia. Neste Catálogo a cada jesuíta é atribuído um número, correspondente ao nome. O Catálogo Segundo é organizado por número, sendo omissos os nomes correspondentes, devido ao caráter reservado dos dados nele contidos. O documento fornece informações acerca do perfil de cada jesuíta, de modo tal que poderíamos defini-lo numa linguagem atual, como uma espécie de perfil psicossomático dos indivíduos membros da Ordem. Com efeito, refere-se a vários aspectos psicológicos e comportamentais: o "juízo", a "prudência", o "talento", a "compleição" (ou temperamento). O Catálogo Terceiro refere-se à situação concreta (numérica, econômica, etc.) das casas ou colégios da Companhia nas diversas Províncias.

O autor dos Catálogos era o Padre Provincial que, para a redação dos mesmos, devia colher informações no

Psicologia: Reflexão e Crítica, 2001, 14(3), pp. 625-633 diálogo com cada sujeito e com os seus Superiores nas residências e nos lugares de atuação missionária. A partir das informações proporcionadas pelos Catálogos - instrumento periódico e sistemático para o conhecimento da situação concreta da Ordem, ao longo do tempo e em todos os lugares - podia ser planejada e organizada a distribuição ou redistribuição dos membros da Companhia no tempo e no espaço, segundo critérios ideais fornecidos pelo saber da Companhia, a mentalidade de seu tempo e a demanda concreta de cada situação.

Para exemplificar, utilizamo-nos da documentação dos Catálogos Trienais referentes ao Brasil (Rodrigues, 15561660), na Província da Bahia, onde, além do colégio de Salvador, existiam várias "residências" dos jesuítas junto às aldeias indígenas. Tendo em vista tais circunstâncias, era importante dispor de sujeitos que tivessem "talentum ad linguas", ou seja, boa capacidade para falar e pregar no idioma dos índios, e "talentum ad concionatum", ou seja, que fossem bons pregadores. Dentre os jesuítas residentes no colégio, era necessária a presença de alguns indivíduos de "compleição melancólica", sendo que o excesso do humor da melancolia predispõe para as atividades intelectuais. Seria preciso inclusive de alguns indivíduos dotados de "compleição fleumática", que os tornaria aptos a realizar "ofícios domésticos". De qualquer forma, o perfil ideal para a atividade missionária no Brasil, quanto ao temperamento, parece ser o "colérico sangüíneo" ou o "colérico melancólico", pois o excesso do humor da cólera predispõe o indivíduo à ação, ao heroísmo, a enfrentar circunstâncias árduas - tão freqüentes no contexto quotidiano da terra de Santa Cruz. Pelo contrário, não poderia haver entre os religiosos muitos “sangüíneos": de fato, esta compleição predispõe o indivíduo para intensa vida sexual e todo tipo de prazeres da carne (para o aprofundamento deste tema vide: Massimi, 2000).

A ocorrência de problemas na vida cotidiana da Companhia, relacionados com as características temperamentais de seus membros, é documentada por algumas cartas reservadas, anexas aos Catálogos. Essas fornecem observações escritas pelos Padres Provinciais solicitando que alguns indivíduos "coléricos adustum" (excessivamente coléricos) deveriam ser removidos de um ou outro local, por serem inadequados e acarretar desequilíbrios no meio da comunidade. Encontram-se também algumas cartas de religiosos, dirigidas ao Padre Geral, solicitando a volta à Europa, sendo que os autores se dizem incapazes de resistir às tentações quotidianamente presentes na convivência nas aldeias (por exemplo, as índias desnudas). Um deles motiva seu pedido por ser incapaz de controlar seu temperamento sangüíneo. 


\section{Conclusão}

Ao decorrer do estudo, evidenciou-se uma questão metodológica que consideramos especialmente relevante para a nossa discussão: na construção do saber elaborado pelos jesuítas, a "experiência psicológica" articulase inevitavelmente em conjunto com outras dimensões da experiência humana (a dimensão somática e a dimensão espiritual), sendo impossível, portanto, concebêla de modo autônomo (conforme pelo contrário entende a Psicologia moderna). Desse modo, é preciso de um grande cuidado para identificar o que é concebido como estritamente "psicológico" e para reconhecer como este é "ordenado" no âmbito de uma estrutura e de uma dinâmica mais complexas, constitutivas, do ser humano em sua totalidade, conforme a visão da época. De fato, nos Exercícios Espirituais e nas demais obras de Inácio de Loyola, os fenômenos propriamente psicológicos, por exemplo, sentimentos como tristeza, medo, ou alegria -, estão associados a experiências de natureza espiritual (chamadas "consolação" e "desolação"), sem que haja confusão e identificação entre umas e outras. O risco de leituras reducionistas, ou no sentido psicológico ou no sentido espiritualista, está, portanto sempre presente na análise desta literatura.

De qualquer forma, é inegável a contribuição que a produção jesuítica representa no âmbito do processo cultural que - ao longo dos séculos XVI e XVII - visa a obter a construção de formas novas de conhecimento do homem e da sociedade. Pois, conforme bem assinala Maravall (1997), a característica peculiar que o conhecimento de si mesmo adquire neste período, é o valor "tático e eficaz, segundo o qual não se vai em busca de uma verdade última, mas de regras que permitem àqueles que as alcancem adequar-se às circunstâncias da realidade entre as quais se move." (1997, p. 123). Conhecer-se a si mesmo, em suma, para tornar-se dono de si e da realidade ao redor, conhecer-se para refazer-se.

\section{Referências}

Anchieta, J. (1988). Cartas, informações, fragmentos históricos e sermões. Belo Horizonte: EDUSP-Itatiaia.

Andrade, A. A. B. (1981). Contributos para a bistória da mentalidade pedagógica portuguesa. Lisboa: Imprensa Nacional-Casa da Moeda.

Aquaviva, C. (1893). Industriae ad curandos animi morbos, Manuscrito n. 429, da Opera Nostrorum, ARSI, folhas 33-42 e em Institutum, vol. 2.

Aquaviva, C. (1893). Instructio ad reddendam rationem conscientiae iuxta morem Societatis Iesu. Manuscrito n. 429, da Opera Nostrorum, ARSI, folhas 33-42 e em Institutum, Vol. 2.

Aristóteles (1994). Problemata XXX. Em P. Louis (Org.), Problémes (Vol. 3). Paris: Les Belles Lettres.

Aristóteles (1993). Rethorique (Vol. 2). Paris: Belles Lettres.
Aristóteles (1996). Ética a Nicomaco. Livro segundo. Edição Pensadores: Abril Cultural.

Barreto, L. F. (1983). Descobrimentos e renascimento. Formas de pensar e de ser nos séculos XV e XVI. Lisboa: Imprensa Nacional-Casa da Moeda.

Caeiro, F. G. (1982). O pensamento filosófico do século XVI ao século XVIII em Portugal e no Brasil. Acta do l Congresso Luso-Brasileiro de Filosofia (pp. 51-90). Braga, Portugal.

Caeiro, F. G. (1989) El problema de las raíces históricas. Em E. M. Barba (Org.), Iberoamerica, una comunidad (pp. 377-389). Madrid: Ediciones de Cultura Hispânica.

Cassirer, E. (1977). Individuo e cosmo nella Filosofia del Rinascimento. Firenze: La Nuova Itália.

Crombie, A. (1987). Historia de la ciencia, siglos XIII-XVII (Vol. 2). Madrid: Alianza Universitaria.

Delumeau, J. (1994). A civilização do Renascimento. Lisboa: Estampa.

Ficino, M. (1995). De le tre vite cioé a qual guisa si possono le persone letterate mentenere in sanitá. Per qual guisa si possa l'huomo prolungare la vita, con che arte , e mezzi, ci possiamo questa sana e lunghissima vita prolungare per via del ciello. Milão: Rusconi.

Garin, E. (1995). L'uomo del Rinascimento. Bari: Laterza.

Giard, L. (1995). Les jésuites á la Renaissance. Système éducatif et production du savoir. Paris: PUF, Bibliothèque d'histoire des sciences.

Giard, L. \& Vaucelles, L. (1996). Les jésuites à l'âge baroque, 1540-1640. Grenoble: Millon Historie des jésuites de la Renaissance aux Lumieres.

Gilardi, L. M. (1995). Autobiografie di gesuiti in Italia (1540-1640). Storia e interpretazione. Archivum Historicum Societatis Iesu, 64, 3-38.

Góis, M. (1593a). Commentarii collegii conimbricensis Societatis Iesu, In libros Aristotelis qui parva naturalia appellantur. Lisboa: Simão Lopes.

Góis, M. (1593b). Disputas do curso sobre os livros da moral da ética a Nicomaco, de Aristóteles em que se contêm alguns dos principais capitulos da Moral. Lisboa: Simão Lopes.

Góis, M. (1602). Commentarii collegii conimbricensis Societati Iesu, In tres libros de anima. Veneza: Itália.

Góis, M. (1607). Commentarii collegii conimbricensis Societatis Iesu, In Libro de generatione et corruptione Aristotelis Stagiritae nunc recens omni diligentia recogniti et emendati.Veneza: Tipografia Vincenzo Amadino.

Klibansky, R., Panofsky, E. \& Saxl, F. (1983). Saturno e la melancolia. Torino: Einaudi.

Hanke, L. (1985). La bumanidad es uma. México: Fondo de la Cultura Economica.

Iparraguirre, I., SI. (1961). Répertoire de spiritualié ignatienne, de la mort de S. Ignace à celle du P. Aquaviva, 1556-1615. Roma: Institutum Historicum Societatis Iesu.

Iparraguirre, I., SI. (1967). Comentarios de los ejercicios ignacianos (siglos XVTXVIII), Repertorio critico. Roma: Institutum Historicum Societais Iesu.

Lamalle, E., SI. (1981-1982). L' archivio di un grande ordine religioso. L'archivio generale della Compagnia di Gesú. Archiva Ecclesiae, XXIX a XXV, 1, 89-120.

Loyola, I. (1993). Cartas. São Paulo: Loyola.

Loyola, I. (1982). Obras completas, n. 86. Madrid: Bibliotecas Autores Cristianos.

Maravall, J. A. (1997). A cultura do Barroco. São Paulo: EDUSP.

Martins, A. M. (1989). Conimbricenses. Logos, 2, 1112-1126.

Massimi, M. (1983). Marcus Marulus, i suoi Maestri e la "Psychologia de ratione animae humanae". Storia e critica della Psicologia, IV(1), 27-41.

Massimi, M. (2000). La psicologia dei temperamenti nei Cataloghi Triennali dei gesuiti in Brasile. Physis, Rivista Internazionale di Storia della Scienza,(Vol.37, 1, pp.137-149).

Nobrega, M. (1988). Cartas do Brasil. Belo Horizonte: EDUSP - Itatiaia.

Paim, A. (1974). História das idéias filosóficas no Brasil. São Paulo: EDUSP.

Rodrigues, M. A. (1985). Do humanismo à contra-reforma em Portugal. Revista de História das Idéias, $V$, 40-52.

Rodrigues, P. (1556-1660). Catalogus trienales et breves, Bras 5-I. Manuscrito não publicado. Archivio Storico della Compagnia di Gesú, Roma, Itália.

San Juan, H. (1989). Examen de ingenios. Madrid: Catedra-Letras Hispánicas. 
Santos, M. A. M. A. (1955). Apontamentos à margem das conclusões impressas dos Mestres Jesuítas portugueses de Filosofia. Revista Portuguesa de Filosofia, 10, 561-567.

Séneca, L. A. (1980). Cartas a Lucilio Nuestros clasicos, n. 53. México: Universidade Autonoma de México.

Séneca, L. A. (1994). Sobre a tranqüilidade da alma. Sobre o ócio. Nova Alexandria: São Paulo.

Tavares, S. (1948). O colégio das artes e a filosofia em Portugal. Revista Portuguesa de Filosofia, IV(3), 227-240.
Tomás De Aquino (1980). Suma teológica. Caxias do Sul, RS: Escola Superior de Teologia, Editora Sulina, Universidade de Caxias do Sul, UFRGS.

Verheecke, M. (1984). L'itineraire du chrétien d'après les Exercices spirituels d'Ignace de Loyola et ses presupposés anthropologiques. Louvain La Neuve: Diffusion Centre Cerfaux-Lefort.

Sobre a autora

Marina Massimi é Psicóloga, Pesquisadora de CNPq, Doutora em Psicologia Experimental pela Universidade de São Paulo, Professora de História da Psicologia no Curso de Psicologia na USP de Ribeirão Preto. 